\title{
酚酸和氮素交互作用下欧美杨107细根形态特征
}

\author{
朱婉芮 ${ }^{1}$ 汪其同 ${ }^{1}$ 刘梦玲 ${ }^{1}$ 王华田 ${ }^{1,2}$ 王延平 ${ }^{1,2^{*}}$ 张光灿 ${ }^{1,2}$ 李传荣 ${ }^{1,2}$
}

${ }^{1}$ 山东农业大学林学院, 山东泰安 $271018 ;{ }^{2}$ 国家林业局泰山森林生态系统定位研究站, 山东泰安 271018

摘 要 树木细根生长与根际过程的关系十分密切。该研究仿生欧美杨107 (Populus $\times$ euramericana 'Neva')人工林根际土壤 酚酸沉降与氮素有效性变化, 通过设置 3 种酚酸梯度 $(0 X 、 0.5 X 、 1.0 X, X$ 为田间土壤酚酸含量 $)$ 与 3 种氮素水平 $\left(\right.$ 缺氮 $0 \mathrm{mmol} \cdot \mathrm{L}^{-1}$ 、 正常氮 $10 \mathrm{mmol} \cdot \mathrm{L}^{-1}$ 、高氮 $\left.20 \mathrm{mmol} \cdot \mathrm{L}^{-1}\right)$, 探究酚酸和氮素对欧美杨 107 细根形态的影响, 以期为阐明树木根系生长对根-土界 面过程的响应奠定基础。结果表明: (1)在无酚酸 $(0 X)$ 环境中, 缺氮和高氮均可抑制欧美杨107细根生长, 尤其对 1-3级细根的影 响更为显著。比根长随氮素水平升高逐渐减小, 但其他细根特征并未呈现与氮素水平的线性关系。(2) $0.5 X$ 和 $1.0 X$ 酚酸梯度相 比，欧美杨107的1-2级细根直径和体积随酚酸浓度增加而显著增大 $(p<0.05)$ 。酚酸和氮素对杨树细根的影响存在交互作用， 1-2级细根直径、体积受酚酸的影响显著, 而4-5级细根长度、表面积受氮素影响显著。双因素方差分析结果表明, 酚酸和氮 素对细根形态建成具有协同或拮抗效应。(3)主成分分析(PCA)和几余分析(RDA)结果表明, 在酚酸和氮素交互效应下, 杨树 1-3级、4级、5级细根之间具有显著的形态差异。第一主成分主要体现细根受食性状特征，可解释细根形态变异的 $60.9 \%$ 的 信息; 第二主成分主要体现细根形态构建特征, 可解释 $25.3 \%$ 的信息。杨树细根形态变化与根序高度相关, N素影响杨树细根 形态的主效应较酚酸更强。因此, 根际环境中酚酸累积和氮素有效性变化会影响杨树细根的形态构建和细根对水分、养分的 吸收, 而氮素有效性是影响杨树细根生长的重要因素, 开展杨树人工林土壤养分管理是林分生产力长期维持的关键。

关键词 细根形态, 氮素有效性, 酚酸根际沉降, 杨树根序, 根土互作

引用格式: 朱婉芮, 汪其同, 刘梦玲, 王华田, 王延平, 张光灿, 李传荣 (2015). 酚酸和氮素交互作用下欧美杨107细根形态特征. 植物生态学报, 39, 1198-1208. doi: 10.17521/cjpe.2015.0116

\section{Interactive effects of phenolic acid and nitrogen on morphological traits of poplar (Populus $\times$ euramericana 'Neva') fine roots}

ZHU Wan-Rui ${ }^{1}$, WANG Qi-Tong ${ }^{1}$, LIU Meng-Ling ${ }^{1}$, WANG Hua-Tian ${ }^{1,2}$, WANG Yan-Ping ${ }^{1,2^{*}}$, ZHANG Guang-Can ${ }^{1,2}$, and LI Chuan-Rong ${ }^{1,2}$

${ }^{1}$ Forestry College of Shandong Agricultural University, Tai'an, Shandong 271018, China; and ${ }^{2}$ Taishan Forest Ecosystem Research Station of State Forestry Administration, Tai'an, Shandong 271018, China

\section{Abstract}

Aims The relationship between rhizosphere process and fine root growth is very close but still obscure. In poplar plantation, phenolic acid rhizodeposition and soil nutrient availability were considered as two dominant factors of forest productivity decline. It is very hard to separate them in the field and they might show an interactive effect on fine root growth. The objective of this study is to examine the influence of phenolic acids and nitrogen on branch orders of poplar fine roots and to give a deeper insight into how the ecological process on root-soil interface affected fine root growth as well as plantation productivity.

Methods The cuttings of health annual poplar seedlings (I-107, Populus $\times$ euramericana 'Neva') serve as experiment materials, and were cultivated under nine conditions, including three concentration of phenolic acids at $0 X, 0.5 X, 1.0 X$ (here, $X$ represented the contents of phenolic acids in the soil of poplar plantation) and three concentration of nitrogen at $0 \mathrm{mmol} \cdot \mathrm{L}^{-1}, 10 \mathrm{mmol} \cdot \mathrm{L}^{-1}, 20 \mathrm{mmol} \cdot \mathrm{L}^{-1}$, based on Hoagland solution. The roots were all separated from poplar seedlings after 35 days, and 30 percent of total fine roots of every treatment were taken as fine root samples. These fine roots were grouped according to 1 to 5 branch orders, and then the morphological traits of each group of fine roots were scanned via root analyzer system (WinRHIZO, Regent Instruments Company, Quebec, Canada) including total length, surface area, volume and average diameter. Meanwhile, the dry mass of fine root samples of every order was measured to calculate specific root length (SRL), root tissue density

收稿日期Received: 2015-03-31 接受日期Accepted: 2015-09-20

* 通讯作者Author for correspondence (E-mail: wangyp@sdau.edu.cn) 
(RTD). All data were analyzed via SPSS 17.0 software, and interactive effect of phenolic acids and nitrogen on roots was analyzed through univariate process module. Principal component analysis (PCA) and redundancy analysis (RDA) were conducted via Canoco 4.5 software.

Important findings Under the conditions without phenolic acids application, the fine roots growth was significantly inhibited in deficiency and higher nitrogen treatments, especially for 1-3 order roots. Only specific root length appeared decreased with nitrogen level, and other traits of fine roots did not demonstrate linear relationship with nitrogen concentrations. Compared to $0.5 \mathrm{X}$ phenolic acids treatment, $1.0 \mathrm{X}$ phenolic acids significantly promoted the diameter and volume of $1-2$ order roots $(p<0.05)$. Both phenolic acids and nitrogen demonstrated influence on poplar fine root traits. However, the diameter and volume of 1-2 order roots were significantly affected by phenolic acids, while the total length and surface area of 4-5 order roots was affected by nitrogen. Two way ANOVA showed that phenolic acids and nitrogen made a synergistic or antagonistic effect on morphological building of fine roots. Furthermore, PCA and RDA indicated that the interactive effects of phenolic acids and nitrogen led to significant differences among 1-3 order, 4 th order and 5th order of poplar fine roots. The PC1 explained about 60.9 percent of root morphological variance, which was related to foraging traits of roots. The PC2 explained 25.3 percent of variance, which was related to root building properties. The response of poplar roots to phenolic acids and nitrogen was closely related to root order, and nitrogen played more influence on poplar roots than phenolic acids. Thus, phenolic acids and nitrogen level would affect many properties of root morphology and foraging in rhizosphere soil of poplar plantation. But nitrogen availability would serve as a dominant factor influencing root growth, and soil nutrient management should be critical to productivity maintenance of poplar plantation.

Key words fine root morphological traits, nitrogen availability, phenolic acids rhizodeposition, poplar root order, root-soil interaction

Citation: Zhu WR, Wang QT, Liu ML, Wang HT, Wang YP, Zhang GC, Li CR (2015). Interactive effects of phenolic acid and nitrogen on morphological traits of poplar (Populus $\times$ euramericana 'Neva') fine roots. Chinese Journal of Plant Ecology, 39, 1198-1208. doi: $10.17521 /$ cjpe. 2015.0116

细根是森林生态系统中植物营养的源和库 (Bloomfield et al., 1996), 也是植物与土壤密切接触 的部分(Norby \& Jackson, 2000; Block et al., 2006), 由此形成的根-土界面成为生态系统碳氮循环的一 个重要界面(Schweinsberg-Mickan et al., 2012)。研究 表明, 细根生长、死亡和周转除受树种本身的遗传 控制外, 还受到土壤因素的重要影响(Fitter et al., 1996; Hodge, 2004)。细根生产与土壤氮素有效性关 系的假说(郭大立和范萍萍, 2007)暗示细根生长与 土壤氮素有效性之间可能存在非线性关系。此外, 由于土壤生态系统的复杂性, 尤其是根-土界面生 物化学性质的特殊性(Jones et al., 2009), 细根生长 对根际环境的响应十分复杂。例如, 由根系分泌或 植物残体腐解形成的根际碳沉降显著改变了根-土 界面性质(孙悦等, 2014)。酚酸作为根际碳沉降的重 要组分(Rice, 1984), 其化感效应不但影响了植物生 长(Li et al., 2010), 而且影响了土壤氮素循环过程 (Inderjit \& Mallik, 1997; Martens, 2002)。因此, 细根 生长可能受根际土壤碳-氮耦合过程的共同影响。但
迄今为止, 关于根际环境变化对细根生长的影响研 究开展较少。

杨树(Populus) 是我国温带地区的典型速生丰产 林树种，轮伐期8-10年。在生产实践中杨树人工林 培育的主要模式是连作经营, 但由此导致的林分生 产力下降现象非常严重(孙翠玲等, 1995; 刘福德等, 2005)。研究表明, 杨树人工林根际存在显著的酚酸 累积趋势(谭秀梅等, 2008)。根际土壤酚酸的累积对 土壤氮素有效性产生了显著抑制(王延平等，2013; 许坛等, 2014), 反之, 土壤氮素缺乏也促使杨树根 系分泌更多的酚酸(王延平等, 2011)。为此, 王华田 和王延平(2013)构建了连作杨树人工林生产力衰退 机理模型，指出酚酸累积和土壤氮素有效性的耦合 作用可能是导致杨树人工林生产力下降的重要原 因。根系作为地上和地下生态过程联系的枢纽, 细 根生长与森林生产力的关系十分密切(Osmont et al., 2007)。杨树细根形态在连作人工林代际间存在较大 差异(许坛等, 2015), 且1-2级细根生物量在二代人 工林中显著增加。因此, 杨树人工林根际酚酸累积 
和氮素有效性变化可能影响了细根形态及生物量分 配, 进而影响林分生产力形成。当前, 关于杨树细根 对酚酸和氮素的响应规律仍不清楚。本研究试图通 过模拟酚酸环境并设置氮素梯度浓度以仿生欧美杨 107 (Populus $\times$ euramericana 'Neva')人工林根际土 壤环境, 探究酚酸和氮素交互作用对杨树幼苗细根 形态特征的影响, 为阐明根-土界面性质改变对杨 树根系生长的影响提供科学依据, 同时为今后深入 开展人工林根际过程与生产力衰退关系的研究奠定 基础。

\section{1 材料和方法}

\section{1 供试材料及试验设计}

采集杨树(品种欧美杨I-107, Populus $\times$ euramericana 'Neva')一年生插穗(直径 $1.5 \mathrm{~cm}$, 长10 cm), 水培至下端出现根原基, 将插穗转移至栽培盆(上 口径 $20 \mathrm{~cm}$, 高 $17 \mathrm{~cm}$, 底径 $15 \mathrm{~cm}$ ), 以蛭石作为基质 继续培养 40 天以确保插穗形成根系, 选取长势一致 的植株用于试验。本研究为仿生杨树人工林土壤根 际环境, 设计了 3 个氮素水平 $\left(\right.$ 缺氮 $\left(0 \mathrm{mmol} \cdot \mathrm{L}^{-1}\right)$ 、正 常氮 $\left(10 \mathrm{mmol} \cdot \mathrm{L}^{-1}\right)$ 、高氮 $\left.\left(20 \mathrm{mmol} \cdot \mathrm{L}^{-1}\right)\right)$ 和 3 个酚酸水 平 $(0 X$ (无酚酸)、 $0.5 X 、 1.0 X, X$ 为田间土壤酚酸含 量)。

氮素水平设计以Hoagland营养液为基础, 通过 调节 $\mathrm{Ca}\left(\mathrm{NO}_{3}\right)_{2} \cdot 4 \mathrm{H}_{2} \mathrm{O} 、 \mathrm{KNO}_{3}$ 和 $\mathrm{NH}_{4} \mathrm{NO}_{3}$ 的量, 分别形 成上述 3 个氮素浓度梯度。其中, 缺氮营养液用 $\mathrm{KCl}$ 、 $\mathrm{CaCl}_{2}$ 替代 $\mathrm{KNO}_{3} 、 \mathrm{Ca}\left(\mathrm{NO}_{3}\right)_{2}$ 维持离子平衡, 保持其 他元素含量一致。酚酸溶液是依据杨树人工林土壤 内测定的 5 种酚酸含量及各土壤对各酚酸物质的吸 附率(谭秀梅等, 2008; 王延平等, 2010), 在上述3个 氮素水平营养液基础上完成(表1)。试验共形成 9 种 处理, 包括无酚酸环境时氮素的3种处理, 以及酚酸 和氮素双因素影响下的6种处理。
用上述营养液浇灌杨树幼苗，每5天一次，每次 $500 \mathrm{~mL}$ 以使盆内栽培基质完全浸润。每种处理 5 个 重复, 共计 45 株苗木。实验材料培养均是在山东农 业大学全自动温室内进行。

\section{2 试验方法}

\subsection{1 杨树细根采集及根序划分}

将选取的生根杨树幼苗按照上述处理分别培养 35 天后开始细根采集, 抖落根系附着的蛭石, 将全 部根系剪下放入具有标号的自封袋，并迅速储存在 冰盒内带回实验室。首先, 从各处理中按照细根总 数 $30 \%$ 的比例随机抽取根系, 放入 $2-3{ }^{\circ} \mathrm{C}$ 蒸馏水中 反复冲洗。按照 Pregitzer等 (2002) 和 ValenzuelaEstrada等(2008)介绍的方法, 以根系生长发育顺序 区分各等级的细根, 即根系分枝最先端为 1 级根, 其 生长在 2 级根上, 2 级根的母根为 3 级根, 依次类推, 一直区分到 5 级根。把剪下的细根按照根序进行分 组, 依次放在盛有低温蒸馏水的培养血中, 并标记 好处理号及根序号。

\subsection{2 细根形态特征测定}

用根系扫描仪(WinRHIZO, Regent Instruments Company, Quebec City, Canada)扫描各根序细根样 品, 获取细根总长度、总表面积、总体积和平均直 径等形态参数。然后将扫描后的各级根序细根分别 置于烘箱, 于 $70{ }^{\circ} \mathrm{C}$ 烘干至恒质量, 放入干燥器中冷 却至室温, 置于 $1 / 1000$ 天平称量细根干质量。根据 长度、体积和干质量分别计算细根比根长 $\left(\mathrm{m} \cdot \mathrm{g}^{-1}\right)$ 、 根组织密度 $\left(\mathrm{g} \cdot \mathrm{cm}^{-3}\right)$ 等参数。

\section{3 数据处理}

采用SPSS 17.0软件中的Means过程, 计算细根 形态指标平均值和标准误差, 并调用最小显著差异 法 $(L S D)$ 分析无酚酸环境下 3 个氮素水平各细根形态 指标的差异显著性 $(\alpha=0.05)$ 。通过SPSS中Univariate 过程对酚酸和氮素影响下各根序细根形态特征指标

表1 酚酸浓度设定

Table 1 Phenolic acid concentration setting in the treatment solutions

\begin{tabular}{|c|c|c|c|c|c|c|}
\hline & & $\begin{array}{c}\text { 对羟基苯甲酸 } \\
p \text {-hydroxybenzoic acid }\end{array}$ & $\begin{array}{l}\text { 香草醛 } \\
\text { Vanillin }\end{array}$ & $\begin{array}{c}\text { 阿魏酸 } \\
\text { Ferulic acid }\end{array}$ & $\begin{array}{c}\text { 苯甲酸 } \\
\text { Benzoic acid }\end{array}$ & $\begin{array}{c}\text { 肉桂酸 } \\
\text { Cinnamic acid }\end{array}$ \\
\hline 林地土壤内酚酸含量 & & 152.00 & 10.40 & 6.50 & 20.60 & 1.95 \\
\hline $\begin{array}{l}\text { Content of phenolic acid in field soil }\left(\mu \mathrm{g} \cdot \mathrm{g}^{-1}\right) \\
\text { 土壤酚酸吸附率 } \\
\text { Absorption rate of phenolic acid in soil }(\%)\end{array}$ & & 61.66 & 93.78 & 89.30 & 37.85 & 94.41 \\
\hline 酚酸含量梯度 & $0.5 X$ & 123 & 6 & 4 & 27 & 1 \\
\hline Gradient of phenolic acid content $\left(\mu \mathrm{g} \cdot \mathrm{mL}^{-1}\right)$ & $1.0 X$ & 247 & 11 & 7 & 54 & 2 \\
\hline
\end{tabular}

$X$ 为田间土壤酚酸含量。

$X$ represents the contents of phenolic acids in the soil of poplar plantation.

www.plant-ecology.com 
进行双因素方差分析, 并采用Duncan新复极差法对 交互效应显著性进行检验 $(\alpha=0.05)$ 。采用Canoco 4.5 软件的主成分分析(PCA)功能, 确定细根形态变 化的主分量并计算其载荷值。将各根序细根形态变 化主分量与环境因子(酚酸和氮素)结合, 采用 Canoco 4.5 软件的咒余分析(RDA)对细根形态与酚 酸、氮素的相关性进行分析, 确定影响细根形态的 主效应。

\section{2 结果和分析}

\section{1 氮素对杨树细根形态特征的影响}

表2显示了无酚酸添加时不同氮素水平(单因 素)对杨树细根各级根序细根形态的影响。总体上, 缺氮和高氮两种水平下各根序细根总长度、总表面 积、总体积小于正常氮水平, 但缺氮和高氮之间大 部分未表现出显著差异。1-2级细根平均直径在正常 氮水平下显著大于缺氮和高氮 $(p<0.05)$, 但3-5级 细根平均直径未表现出显著差异。此外, 1-3级细根 干质量呈现正常等氮显著高于高氮和缺氮 $(p<$ 0.05), 而4-5级细根干质量则差异不显著。各根序细 根比根长总体呈现随氮素水平升高而减小的趋势,
1-3细根组织密度在氮素水平间差异显著，而4-5级 细根差异不显著。

\section{2 酚酸和氮素对杨树细根形态的影响}

从图 1 可以看出, 在 $0.5 X$ 酚酸环境中, 3 种氮素 水平间 1-3级细根总长度的差异未达到显著水平, 但平均直径、表面积和体积的差异显著 $(p<0.05)$; 尤其是细根表面积在缺氮和高氮时均被显著抑制 $(p<0.05)$ 。在此酚酸浓度下, 4 级细根长度和表面积 在缺氮时被显著促进，而5级细根各形态指标均呈 现正常氮水平下较大。在 $1.0 X$ 酚酸环境中, 细根形 态参数随氮素梯度的变化与 $0.5 X$ 酚酸环境相似, 但 是 4 级和 5 级细根形态在不同氮素水平间总体不显 著。可见，酚酸和氮素对细根长度、直径、体积等 形态特征存在交互作用, 4-5级细根受这种交互作用 的影响更为明显。不同酚酸浓度下杨树细根形态也 存在一定差异, 例如, 高氮时, $1.0 X$ 酚酸对 2 级细根长 度、表面积和体积具有显著促进作用，同时3级细根 表面积和体积在此酚酸浓度下也较大。该规律在正 常氮水平下也有体现，1-2级细根体积均受酚酸的显 著促进。这说明, 酚酸对低级细根体积的影响较为显 著，而氮素对高级细根长度、表面积等影响较大。

表2 不同根序细根形态指标对氮素的响应

Table 2 The response of morphological traits of different order fine roots to the nitrogen treatments

\begin{tabular}{|c|c|c|c|c|c|c|c|c|}
\hline $\begin{array}{l}\text { 根序 } \\
\text { Root } \\
\text { order }\end{array}$ & $\begin{array}{c}\text { 氮素水平 } \\
\text { Nitrogen level } \\
\left(\mathrm{mmol} \cdot \mathrm{L}^{-1}\right)\end{array}$ & $\begin{array}{c}\text { 根长度 } \\
\text { Total root } \\
\text { length } \\
(\mathrm{cm})\end{array}$ & $\begin{array}{c}\text { 根表面积 } \\
\text { Total root } \\
\text { surface area } \\
\left(\mathrm{cm}^{2}\right)\end{array}$ & $\begin{array}{c}\text { 根体积 } \\
\text { Total root } \\
\text { volume } \\
\left(\mathrm{cm}^{3}\right)\end{array}$ & $\begin{array}{c}\text { 平均直径 } \\
\text { Average } \\
\text { diameter } \\
(\mathrm{mm})\end{array}$ & $\begin{array}{c}\text { 根干质量 } \\
\text { Root dry } \\
\text { mass } \\
(\mathrm{g})\end{array}$ & $\begin{array}{c}\text { 比根长 } \\
\text { Specific root } \\
\text { length } \\
\left(\mathrm{m} \cdot \mathrm{g}^{-1}\right)\end{array}$ & $\begin{array}{c}\text { 根组织密度 } \\
\text { Root tissue } \\
\text { density } \\
\left(\mathrm{g} \cdot \mathrm{cm}^{-3}\right)\end{array}$ \\
\hline \multirow[t]{3}{*}{1} & 0 & $534.51 \pm 58.78^{\mathrm{a}}$ & $28.93 \pm 2.11^{\mathrm{a}}$ & $0.13 \pm 0.005^{\mathrm{a}}$ & $0.17 \pm 0.064^{\mathrm{a}}$ & $0.013 \pm 0.000^{\mathrm{a}}$ & $323.00 \pm 12.66^{\mathrm{a}}$ & $0.114 \pm 0.010^{\mathrm{ab}}$ \\
\hline & 10 & $822.03 \pm 65.15^{\mathrm{b}}$ & $55.41 \pm 9.47^{\mathrm{b}}$ & $0.41 \pm 0.007^{\mathrm{b}}$ & $0.23 \pm 0.013^{\mathrm{b}}$ & $0.028 \pm 0.002^{\mathrm{b}}$ & $287.53 \pm 4.28^{\mathrm{b}}$ & $0.091 \pm 0.015^{\mathrm{a}}$ \\
\hline & 20 & $389.77 \pm 48.70^{\mathrm{a}}$ & $23.55 \pm 2.28^{\mathrm{a}}$ & $0.12 \pm 0.011^{\mathrm{a}}$ & $0.18 \pm 0.025^{\mathrm{a}}$ & $0.014 \pm 0.002^{\mathrm{a}}$ & $246.51 \pm 37.71^{b}$ & $0.146 \pm 0.001^{\mathrm{b}}$ \\
\hline \multirow[t]{3}{*}{2} & 0 & $716.81 \pm 49.22^{\mathrm{a}}$ & $42.01 \pm 2.90^{\mathrm{a}}$ & $0.19 \pm 0.013^{\mathrm{a}}$ & $0.19 \pm 0.001^{\mathrm{a}}$ & $0.023 \pm 0.003^{\mathrm{a}}$ & $269.07 \pm 36.03^{\mathrm{a}}$ & $0.113 \pm 0.003^{\mathrm{a}}$ \\
\hline & 10 & $871.82 \pm 15.89^{\mathrm{a}}$ & $72.59 \pm 3.10^{b}$ & $0.26 \pm 0.017^{\mathrm{b}}$ & $0.25 \pm 0.011^{b}$ & $0.042 \pm 0.002^{b}$ & $228.89 \pm 18.80^{\mathrm{ab}}$ & $0.085 \pm 0.001^{b}$ \\
\hline & 20 & $428.53 \pm 61.70^{\mathrm{b}}$ & $39.30 \pm 1.34^{\mathrm{a}}$ & $0.23 \pm 0.008^{\mathrm{ab}}$ & $0.21 \pm 0.006^{\mathrm{a}}$ & $0.023 \pm 0.001^{\mathrm{a}}$ & $185.39 \pm 10.71^{b}$ & $0.108 \pm 0.001^{\mathrm{a}}$ \\
\hline \multirow[t]{3}{*}{3} & 0 & $249.26 \pm 19.75^{\mathrm{a}}$ & $16.37 \pm 0.22^{\mathrm{a}}$ & $0.10 \pm 0.007^{\mathrm{a}}$ & $0.24 \pm 0.016^{\mathrm{a}}$ & $0.013 \pm 0.001^{\mathrm{a}}$ & $184.68 \pm 22.25^{\mathrm{a}}$ & $0.104 \pm 0.004^{\mathrm{a}}$ \\
\hline & 10 & $462.39 \pm 52.25^{\mathrm{b}}$ & $28.30 \pm 3.85^{\mathrm{b}}$ & $0.22 \pm 0.014^{\mathrm{b}}$ & $0.30 \pm 0.037^{\mathrm{a}}$ & $0.026 \pm 0.000^{\mathrm{b}}$ & $146.59 \pm 11.16^{\mathrm{ab}}$ & $0.118 \pm 0.006^{\mathrm{ab}}$ \\
\hline & 20 & $179.04 \pm 16.34^{\mathrm{a}}$ & $16.42 \pm 1.27^{\mathrm{a}}$ & $0.14 \pm 0.026^{\mathrm{a}}$ & $0.29 \pm 0.003^{\mathrm{a}}$ & $0.017 \pm 0.002^{\mathrm{a}}$ & $111.33 \pm 2.83^{b}$ & $0.129 \pm 0.005^{\mathrm{b}}$ \\
\hline \multirow[t]{3}{*}{4} & 0 & $38.28 \pm 4.84^{\mathrm{a}}$ & $4.39 \pm 0.30^{\mathrm{a}}$ & $0.06 \pm 0.002^{\mathrm{a}}$ & $0.32 \pm 0.016^{\mathrm{a}}$ & $0.006 \pm 0.000^{\mathrm{a}}$ & $75.49 \pm 7.93^{\mathrm{a}}$ & $0.108 \pm 0.002^{\mathrm{a}}$ \\
\hline & 10 & $43.26 \pm 4.42^{\mathrm{b}}$ & $5.62 \pm 0.47^{\mathrm{ab}}$ & $0.07 \pm 0.009^{b}$ & $0.42 \pm 0.037^{\mathrm{a}}$ & $0.008 \pm 0.003^{\mathrm{a}}$ & $63.54 \pm 5.19^{b}$ & $0.122 \pm 0.005^{\mathrm{a}}$ \\
\hline & 20 & $39.29 \pm 4.19^{b}$ & $4.52 \pm 0.91^{\mathrm{b}}$ & $0.04 \pm 0.011^{\mathrm{a}}$ & $0.39 \pm 0.016^{\mathrm{a}}$ & $0.005 \pm 0.002^{\mathrm{a}}$ & $60.92 \pm 1.38^{\mathrm{b}}$ & $0.130 \pm 0.003^{\mathrm{a}}$ \\
\hline \multirow[t]{3}{*}{5} & 0 & $32.85 \pm 1.14^{\mathrm{a}}$ & $7.41 \pm 0.44^{\mathrm{a}}$ & $0.17 \pm 0.024^{\mathrm{a}}$ & $0.74 \pm 0.018^{\mathrm{a}}$ & $0.032 \pm 0.001^{\mathrm{a}}$ & $12.58 \pm 1.83^{\mathrm{a}}$ & $0.155 \pm 0.004^{\mathrm{a}}$ \\
\hline & 10 & $48.15 \pm 4.71^{\mathrm{a}}$ & $13.85 \pm 1.63^{\mathrm{a}}$ & $0.47 \pm 0.046^{\mathrm{a}}$ & $1.03 \pm 0.056^{\mathrm{a}}$ & $0.043 \pm 0.003^{\mathrm{a}}$ & $9.85 \pm 1.06^{\mathrm{b}}$ & $0.114 \pm 0.284^{\mathrm{a}}$ \\
\hline & 20 & $28.24 \pm 11.61^{\mathrm{a}}$ & $7.74 \pm 4.25^{\mathrm{a}}$ & $0.17 \pm 0.118^{\mathrm{a}}$ & $0.74 \pm 0.136^{\mathrm{a}}$ & $0.024 \pm 0.016^{\mathrm{a}}$ & $8.69 \pm 0.49^{b}$ & $0.140 \pm 0.003^{\mathrm{a}}$ \\
\hline
\end{tabular}

不同字母表示同级根序细根在不同氮水平下形态差异显著 $(p<0.05)$ 。

Different lowercase letters indicate significant differences of fine roots morphological traits among different nitrogen treatments $(p<0.05)$. 

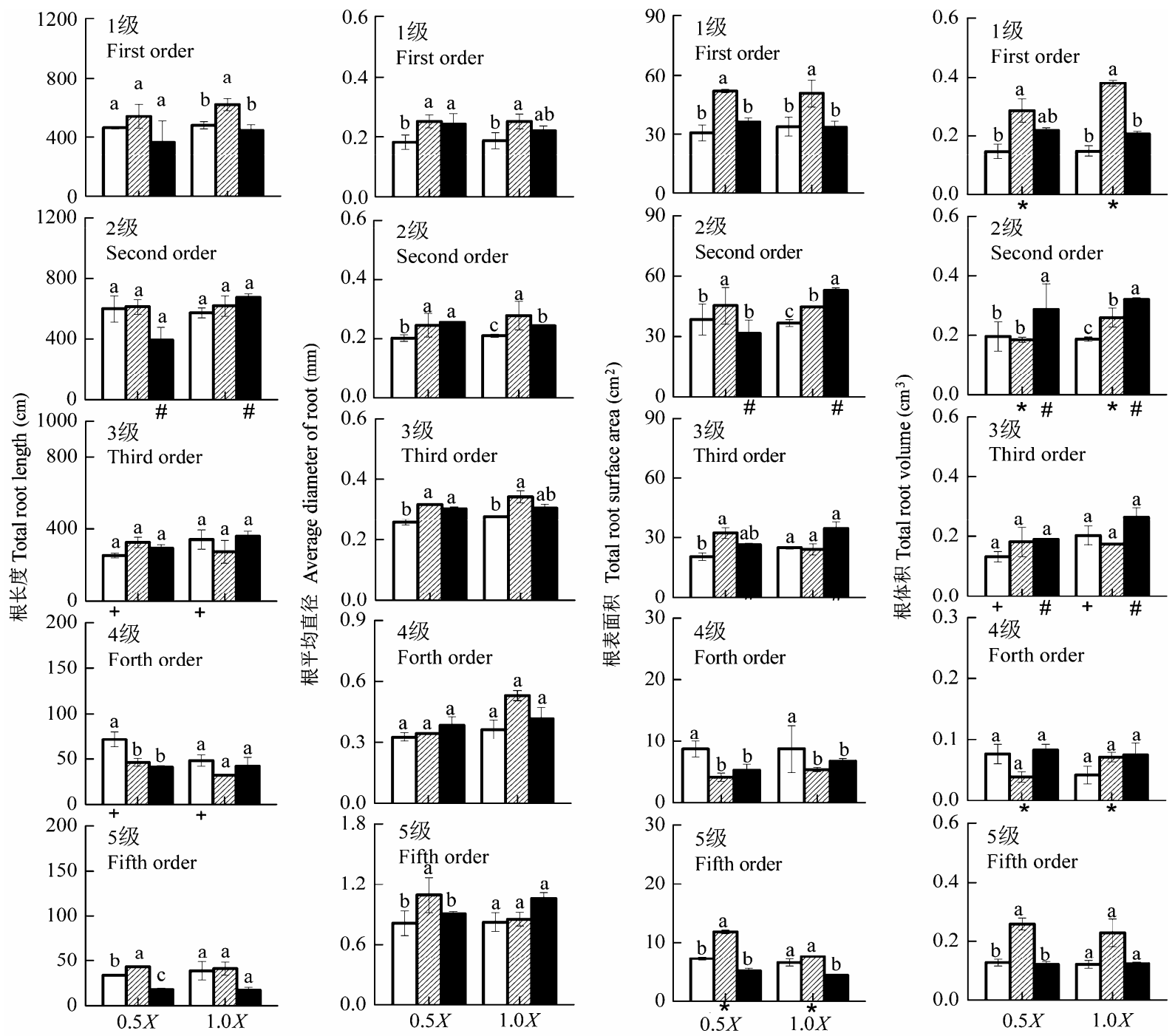

酚酸含量梯度 The gradient of phenolic acid content

氮素水平 Nitrogen level: $\square 0 \mathrm{mmol} \cdot \mathrm{L}^{-1}$ 西 $10 \mathrm{mmol} \cdot \mathrm{L}^{-1} 20 \mathrm{mmol} \cdot \mathrm{L}^{-1}$

图1 酚酸和氮素影响下杨树各根序细根形态特征(平均值土标准误差)。小写字母分别表示 $0.5 X$ 和 $1.0 X$ 酚酸环境中 $(X$ 为田间土 壤酚酸含量), 3 种氮素水平间的差异显著性, 不同字母表示差异显著 $(p<0.05)$ 。,$*$, \#分别表示缺氮 $\left(0 \mathrm{mmol} \cdot \mathrm{L}^{-1}\right)$ 、正常氮 $(10$ $\left.\mathrm{mmol} \cdot \mathrm{L}^{-1}\right)$ 、高氮 $\left(20 \mathrm{mmol} \cdot \mathrm{L}^{-1}\right)$ 时，两酚酸浓度间具有显著差异 $(p<0.05)$ 。

Fig. 1 The fine root morphological characteristics in the interaction of phenolic acid and nitrogen treatments $(m e a n=S E)$. Different lowercase letters and capital letters represent significant difference among three nitrogen treatments under $0.5 X$ and $1.0 X$ phenolic acids respectively $(p<0.05)$, here $X$ represents the contents of phenolic acids in the soil of poplar plantation. Three symbols,,$+ *$ and $\#$, represent significant difference between two treatments of phenolic acids under nitrogen deficiency $\left(0 \mathrm{mmol} \cdot \mathrm{L}^{-1}\right)$, normal nitrogen $\left(10 \mathrm{mmol} \cdot \mathrm{L}^{-1}\right)$ and high nitrogen $\left(20 \mathrm{mmol} \cdot \mathrm{L}^{-1}\right)$, respectively.

从图2可以看出，在 $0.5 X$ 酚酸环境中，1-3级细 根干质量和根组织密度在不同氮素水平间均未呈现 显著差异，而4-5级细根差异显著; 各根序细根的 比根长则呈现随氮素水平升高而显著降低的趋势 $(p<0.05)$ 。在1.0X酚酸环境中, 1-3级细根干质量和 根组织密度在不同氮素水平间的差异显著, 而4-5 级细根则不显著; 比根长在不同氮素水平间的差异 也大部分未达到显著水平。可见, 酚酸和氮素对杨
树细根干质量、根组织密度等形态参数存在明显的 交互作用。酚酸对杨树细根形态也具有一定影响，例 如，1-3级细根干质量在正常氮、缺氮和高氮水平下 均能被酚酸显著促进，而4-5级细根受酚酸的影响不 显著。这说明, 根系受酚酸的影响在低级细根中更为 明显。

双因素方差分析表明, 酚酸和氮素对杨树细根 形态影响的交互作用显著(表3)。虽然氮素对杨树 

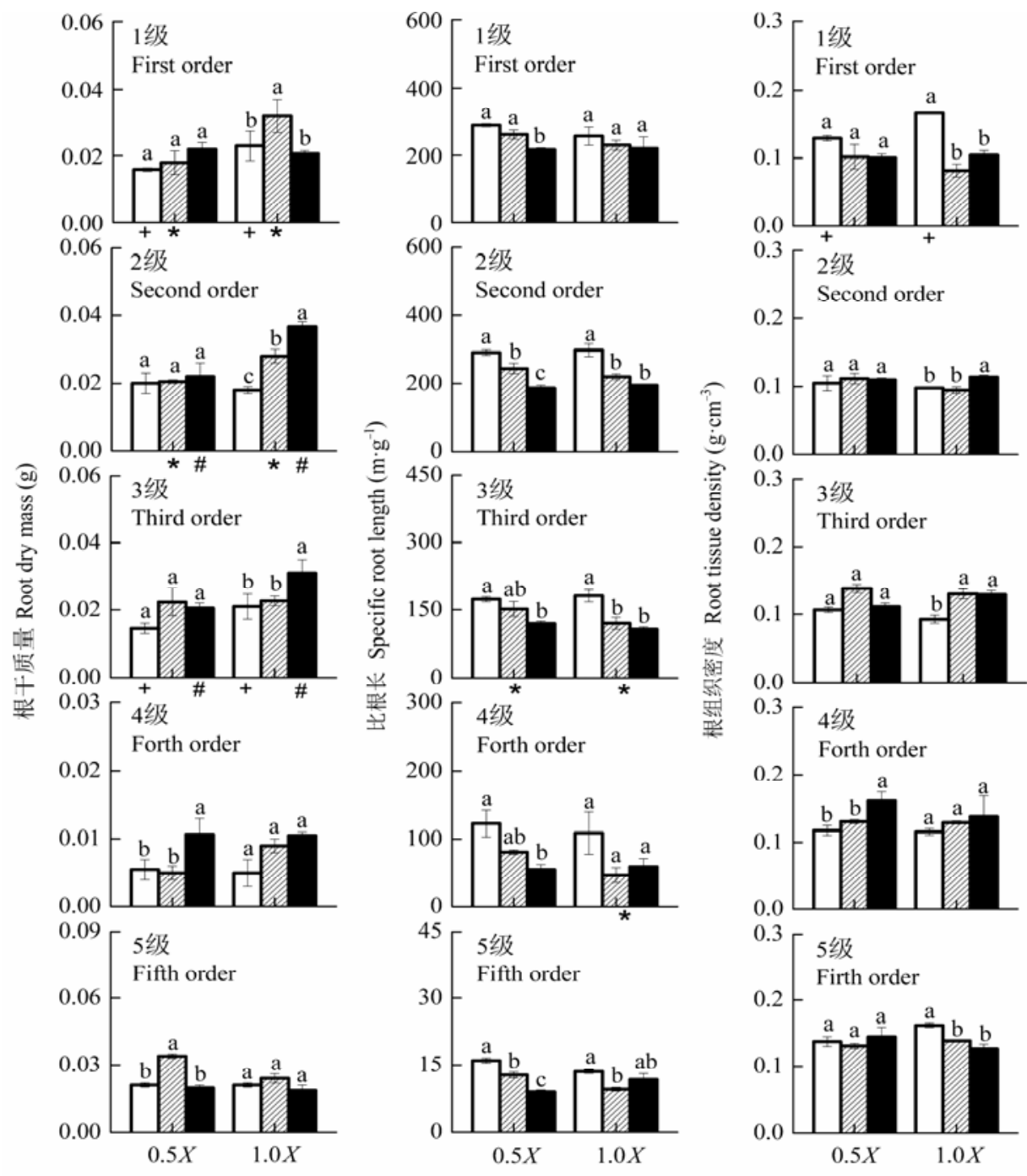

酚酸含量梯度 The gradient of phenolic acid content

氮素水平 Nitrogen level: $\square 0 \mathrm{mmol} \cdot \mathrm{L}^{-1} \mathrm{~m} 10 \mathrm{mmol} \cdot \mathrm{L}^{-1}$

$20 \mathrm{mmol} \cdot \mathrm{L}^{-1}$

图2 酚酸和氮素影响下各根序细根干质量、比根长和组织密度(平均值 \pm 标准误差)。小写字母分别表示 $0.5 X$ 和 $1.0 X$ 酚酸环境 中 $(X$ 为田间土壤酚酸含量), 3 种氮素水平间的差异显著性，不同字母表示差异显著 $(p<0.05) 。+, *$, \#分别表示缺氮 $(0$ $\left.\mathrm{mmol} \cdot \mathrm{L}^{-1}\right) 、$ 正常氮 $\left(10 \mathrm{mmol} \cdot \mathrm{L}^{-1}\right)$ 、高氮 $\left(20 \mathrm{mmol} \cdot \mathrm{L}^{-1}\right)$ 时，两酚酸浓度间具有显著差异 $(p<0.05)$ 。

Fig. 2 The dry mass, specific root length and root tissue density of different fine root orders under the interaction of phenolic acid and nitrogen conditions (mean $\pm S E$ ). Different lowercase letters and capital letters represent significant difference among three nitrogen treatments under $0.5 X$ and $1.0 X$ phenolic acids respectively $(p<0.05)$, here $X$ represents the contents of phenolic acids in the soil of poplar plantation. Three symbols,,$+ *$ and \#, represent significant difference between two treatments of phenolic acids under nitrogen deficiency $\left(0 \mathrm{mmol} \cdot \mathrm{L}^{-1}\right)$, normal nitrogen $\left(10 \mathrm{mmol} \cdot \mathrm{L}^{-1}\right)$ and high nitrogen $\left(20 \mathrm{mmol} \cdot \mathrm{L}^{-1}\right)$, respectively.

1-3级细根长度、直径、表面积、体积等形态特征总 体具有显著影响，而酚酸的影响大部分不显著。此 外, 4-5级细根长度、表面积和比根长受氮素的显著 影响 $(p<0.05)$, 而受酚酸的影响不显著。但是，在酚 酸和氮素的共同作用下, 1 级细根长度和表面积, 1-4 级细根直径, 以及 $1-5$ 级细根比根长均表现出酚酸 和氮素显著的交互作用 $(p<0.05)$ 。例如, 1 级细根长 度虽然受氮素的显著影响 $\left(p_{\mathrm{N}}=0.002\right)$, 但由于酚酸
的影响不显著 $\left(p_{\mathrm{T}}=0.116\right)$, 导致酚酸和氮素交互效 应也未达到显著水平 $\left(p_{(\mathrm{N} \times \mathrm{T})}=0.300\right)$, 说明酚酸和氮 素对细根长度的影响可能存在主效应问题 $\left(p_{\mathrm{N}} 、 p_{\mathrm{T}}\right.$ 、 $p_{(\mathrm{N} \times \mathrm{T})}$ 分别表示酚酸和氮素双因素作用下，氮素、酚 酸、氮素 $\times$ 酚酸对细根形态影响的Duncan检验 $p$ 值)。 同样, 1 级细根比根长虽然均受氮素和酚酸的显著影 响 $\left(p_{\mathrm{N}}=0.018, p_{\mathrm{T}}=0.048\right)$, 但是两者共同作用并未 导致比根长显著变化 $\left(p_{(\mathrm{N} \times \mathrm{T})}=0.852\right)$, 说明酚酸和氮 
表3 酚酸和氮素对细根形态特征的交互效应分析

Table 3 The interaction effect of phenolic acid and nitrogen on morphological traits of poplar fine roots

\begin{tabular}{|c|c|c|c|c|c|c|c|c|}
\hline $\begin{array}{l}\text { 根序 } \\
\text { Root order }\end{array}$ & $\begin{array}{l}\text { 处理 } \\
\text { Treatment }\end{array}$ & $\begin{array}{c}\text { 根长度 } \\
\text { Total root } \\
\text { Length }(\mathrm{cm})\end{array}$ & $\begin{array}{c}\text { 根表面积 } \\
\text { Total root surface } \\
\text { area }\left(\mathrm{cm}^{2}\right)\end{array}$ & $\begin{array}{c}\text { 根体积 } \\
\text { Total root } \\
\text { volume }\left(\mathrm{cm}^{3}\right)\end{array}$ & $\begin{array}{c}\text { 根平均直径 } \\
\text { Average diameter } \\
\text { of root }(\mathrm{mm})\end{array}$ & $\begin{array}{l}\text { 根干质量 } \\
\text { Root dry } \\
\text { mass (g) }\end{array}$ & $\begin{array}{c}\text { 比根长 } \\
\text { Specific root } \\
\text { length }\left(\mathrm{m} \cdot \mathrm{g}^{-1}\right)\end{array}$ & $\begin{array}{c}\text { 根组织密度 } \\
\text { Root tissue } \\
\text { density }\left(\mathrm{g} \cdot \mathrm{cm}^{-3}\right)\end{array}$ \\
\hline \multirow{3}{*}{$\begin{array}{l}\text { 1级 } \\
\text { First order }\end{array}$} & $p_{\mathrm{N}}$ & $0.002^{*}$ & $0.000^{*}$ & $0.000^{*}$ & $0.000^{*}$ & $0.009^{*}$ & $0.018^{*}$ & $0.001^{*}$ \\
\hline & $p_{\mathrm{T}}$ & $0.116^{\mathrm{ns}}$ & $0.559^{\mathrm{ns}}$ & $0.295^{\mathrm{ns}}$ & $0.201^{\mathrm{ns}}$ & $0.023^{*}$ & $0.048^{*}$ & $0.667^{\mathrm{ns}}$ \\
\hline & $p_{(\mathrm{N} \times \mathrm{T})}$ & $0.300^{\mathrm{ns}}$ & $0.394^{\mathrm{ns}}$ & $0.003^{*}$ & $0.867^{\mathrm{ns}}$ & $0.067^{\mathrm{ns}}$ & $0.852^{\mathrm{ns}}$ & $0.008^{*}$ \\
\hline \multirow{3}{*}{$\begin{array}{l}\text { 2级 } \\
\text { Second order }\end{array}$} & $p_{\mathrm{N}}$ & $0.005^{*}$ & $0.015^{*}$ & $0.071^{\mathrm{ns}}$ & $0.001^{*}$ & $0.001^{*}$ & $0.000^{*}$ & $0.009^{*}$ \\
\hline & $p_{\mathrm{T}}$ & $0.041^{*}$ & $0.054^{\mathrm{ns}}$ & $0.569^{\mathrm{ns}}$ & $0.083^{\mathrm{ns}}$ & $0.002^{*}$ & $0.715^{\mathrm{ns}}$ & $0.164^{\mathrm{ns}}$ \\
\hline & $p_{(\mathrm{N} \times \mathrm{T})}$ & $0.015^{*}$ & $0.028^{*}$ & $0.557^{\mathrm{ns}}$ & $0.424^{\mathrm{ns}}$ & $0.001^{*}$ & $0.853^{\mathrm{ns}}$ & $0.011^{*}$ \\
\hline \multirow{3}{*}{$\begin{array}{l}\text { 3级 } \\
\text { Third order }\end{array}$} & $p_{\mathrm{N}}$ & $0.039^{*}$ & $0.014^{*}$ & $0.080^{\mathrm{ns}}$ & $0.003^{*}$ & $0.017^{*}$ & $0.000^{*}$ & $0.000^{*}$ \\
\hline & $p_{\mathrm{T}}$ & $0.481^{\mathrm{ns}}$ & $0.011^{*}$ & $0.046^{*}$ & $0.164^{\mathrm{ns}}$ & $0.035^{*}$ & $0.366^{\mathrm{ns}}$ & $0.931^{\mathrm{ns}}$ \\
\hline & $p_{(\mathrm{N} \times \mathrm{T})}$ & $0.004^{*}$ & $0.012^{*}$ & $0.086^{\mathrm{ns}}$ & $0.923^{\mathrm{ns}}$ & $0.118^{\mathrm{ns}}$ & $0.494^{\mathrm{ns}}$ & $0.023^{*}$ \\
\hline \multirow{3}{*}{$\begin{array}{l}\text { 4级 } \\
\text { Forth order }\end{array}$} & $p_{\mathrm{N}}$ & $0.001^{*}$ & $0.021^{*}$ & $0.503^{\mathrm{ns}}$ & $0.001^{*}$ & $0.097^{\mathrm{ns}}$ & $0.000^{*}$ & $0.052^{\mathrm{ns}}$ \\
\hline & $p_{\mathrm{T}}$ & $0.066^{\mathrm{ns}}$ & $0.764^{\mathrm{ns}}$ & $0.406^{\mathrm{ns}}$ & $0.066^{\mathrm{ns}}$ & $0.379^{\text {ns }}$ & $0.409^{\mathrm{ns}}$ & $0.521^{\mathrm{ns}}$ \\
\hline & $p_{(\mathrm{N} \times \mathrm{T})}$ & $0.220^{\mathrm{ns}}$ & $0.926^{\mathrm{ns}}$ & $0.070^{\mathrm{ns}}$ & $0.220^{\mathrm{ns}}$ & $0.121^{\mathrm{ns}}$ & $0.634^{\mathrm{ns}}$ & $0.819^{\mathrm{ns}}$ \\
\hline \multirow{3}{*}{$\begin{array}{l}5 \text { 级 } \\
\text { Fifth order }\end{array}$} & $p_{\mathrm{N}}$ & $0.005^{*}$ & $0.048^{*}$ & $0.012^{*}$ & $0.067^{\mathrm{ns}}$ & $0.108^{\mathrm{ns}}$ & $0.002^{*}$ & $0.222^{\mathrm{ns}}$ \\
\hline & $p_{\mathrm{T}}$ & $0.631^{\mathrm{ns}}$ & $0.238^{\mathrm{ns}}$ & $0.111^{\mathrm{ns}}$ & $0.453^{\mathrm{ns}}$ & $0.163^{\mathrm{ns}}$ & $0.092^{\mathrm{ns}}$ & $0.876^{\mathrm{ns}}$ \\
\hline & $p_{(\mathrm{N} \times \mathrm{T})}$ & $0.760^{\mathrm{ns}}$ & $0.824^{\mathrm{ns}}$ & $0.552^{\mathrm{ns}}$ & $0.129^{\mathrm{ns}}$ & $0.884^{\mathrm{ns}}$ & $0.124^{\mathrm{ns}}$ & $0.569^{\mathrm{ns}}$ \\
\hline
\end{tabular}

$p_{\mathrm{N}} 、 p_{\mathrm{T}} 、 p_{(\mathrm{N} \times \mathrm{T})}$ 分别表示酚酸和氮素双因素作用下, 氮素、酚酸、氮素 $\times$ 酚酸对细根形态影响的Duncan检验 $p$ 值。 $*, p<0.05 ; \mathrm{ns}, p>0.05$ 。

$p_{\mathrm{N}}, p_{\mathrm{T}}, p_{(\mathrm{N} \times \mathrm{T})}$ represent the significance value of Duncan test on fine root morphological traits of nitrogen, phenolic acids, and interaction of nitrogen and phenolic acids, respectively. *, $p<0.05 ; \mathrm{ns}, p>0.05$.

表4 细根形态指标的主分量载荷

Table 4 Component matrix of fine root growth indices

\begin{tabular}{lcc}
\hline 细根形态指标 & \multicolumn{2}{c}{ 主成分 Principal component } \\
\cline { 2 - 3 } Morphological traits of fine root & 1 & 2 \\
\hline 根长 Total root length & 0.872 & 0.421 \\
根表面积 Total root surface area & 0.912 & 0.542 \\
根体积 Total root volume & 0.239 & 0.916 \\
根直径 Average diameter of root & -0.805 & 0.246 \\
根干质量 Root dry mass & 0.000 & 0.952 \\
比根长 Specific root length & 0.956 & 0.069 \\
根组织密度 Root tissue density & -0.655 & -0.330 \\
\hline
\end{tabular}

素对比根长的影响可能具有补偿效应。

\section{3 酚酸和氮素对杨树细根形态特征影响的主效 应分析}

对酚酸和氮素影响下细根形态特征的PCA分析 表明, 第一主成分可解释细根形态变化 $60.9 \%$ 的信 息量, 其中细根长度、表面积和比根长这 3 个体现细 根受食特征分量的载荷值较高; 第二主成分可解释 细根形态变化约 $25.3 \%$ 的信息量, 体积和干质量这 两个体现细根形态构建特征分量的载荷值较高(表 4)。从排序图中可以看出, 依据不同处理下细根形
态特征变化, 可将1-3级、4级、5级细根在排序轴上 清晰分离, 第一排序轴(PC1)基本体现出细根形态 随根序的变化(图3), 即1-3级、4级、5级细根之间均 具有显著形态差异。对环境因素(酚酸、氮素)与细 根形态特征的冗余分析(图4)表明: 氮素向量对杨树 细根形态特征影响的主效应较大, 酚酸向量的影响 较小(图4)。因此, 本研究设置的环境梯度中, 氮素 $\left(R^{2}=0.078\right)$ 比酚酸 $\left(R^{2}=0.014\right)$ 更能显著影响细根形 态特征。此外, 由于不同根序细根形态特征的显著 差异, 酚酸和氮素对杨树细根的影响呈现与根序的 高度相关性 $\left(R^{2}=0.790\right)$, 根序向量对细根形态特征 的影响也较大(图4)。同时, 酚酸和氮素对细根形态 特征的作用方向不同, 酚酸与细根直径、体积、干 质量和组织密度等形态构建特征呈现正相关, 而氮 素与长度、比根长等决定细根受食性状的形态特征 具有负相关性(图4)。

\section{3 讨论}

氮素对细根生长具有重要调控作用(Osmont $e t$ al., 2007; Ruffel et al., 2011)。关于氮素影响下树木 细根特征的研究较多, 陈海波等(2010)研究了不同 


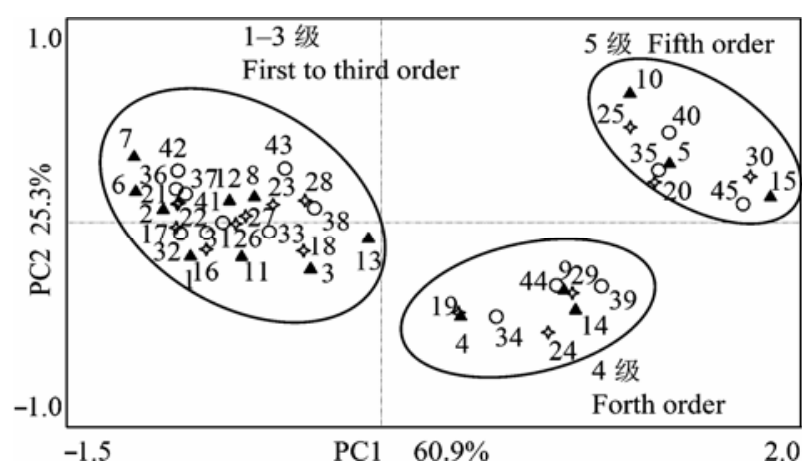

图3 酚酸和氮素处理下不同根序细根形态的主成分分析 (PCA)。数字1-15、16-30、31-45分别表示 $0 X$ (无酚酸)、 $0.5 X$ 、 $1.0 X$ 酚酸处理的各根序细根样品, 其中 $X$ 为田间土壤酚酸含

量。», $\boldsymbol{\Delta}$ 和 $\bigcirc$ 分别表示 $0 \mathrm{mmol} \cdot \mathrm{L}^{-1} 、 10 \mathrm{mmol} \cdot \mathrm{L}^{-1} 、 20$ $\mathrm{mmol} \cdot \mathrm{L}^{-1}$ 三种氮素水平。

Fig. 3 The principal component analysis on morphological traits of poplar fine roots under phenolic acid and nitrogen treatments. The number $1-15,16-30$ and $31-45$ represent the fine root samples under $0 X$ (no phenolic acid), $0.5 X$ and $1.0 X$ phenolic acids, respectively, here $X$ represents the contents of phenolic acids in the soil of poplar plantation. $\diamond, \mathbf{\Delta}$ 和 $\bigcirc$ represent nitrogen deficiency $\left(0 \mathrm{mmol} \cdot \mathrm{L}^{-1}\right)$, normal nitrogen $(10$ $\left.\mathrm{mmol} \cdot \mathrm{L}^{-1}\right)$ and high nitrogen $\left(20 \mathrm{mmol} \cdot \mathrm{L}^{-1}\right)$, respectively.

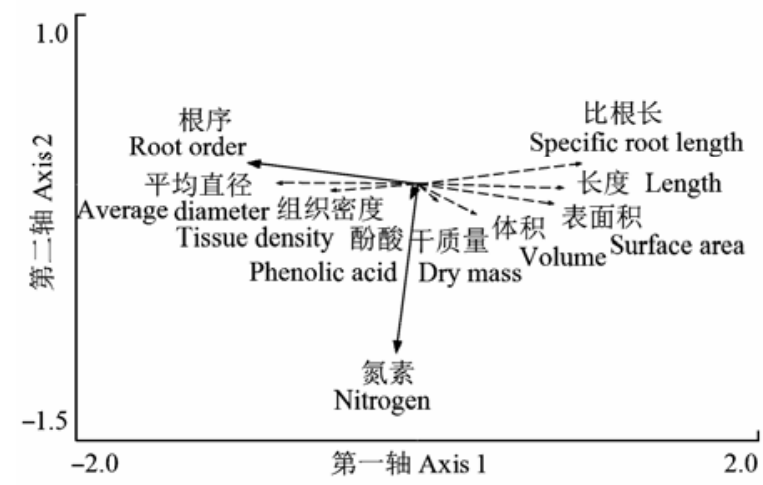

图4 杨树细根形态特征对酚酸和氮素响应的圥余分析。实 线向量分别为环境因子(酚酸和氮素), 虚线向量为细根各形 态参数(指标同表2)。向量越长代表环境因子主效应越强, 环 境向量与根系特征向量的夹角代表它们之间的相关性。环境 向量与细根特征向量同方向表明正相关, 反方向表明负相 关, 垂直表明不相关。

Fig. 4 Redundancy analysis (RDA) on the effects of phenolic acids and nitrogen on morphological traits of poplar fine roots. Real vectors represent environmental factors (phenolic acids and nitrogen), and dotted vectors represent morphological traits of poplar fine roots (the same indices with Table 2). The longer vector is the more important the environmental effects. The correlation between the variables is illustrated by the angle between two vectors. Vectors pointing in nearly the same direction indicate a high positive correlation, vectors pointing in opposite directions have a high negative correlation, and vectors crossing at right angles are related to a near zero correlation.

氮素浓度下 $\left(1 、 8 、 16 \mathrm{mmol} \cdot \mathrm{L}^{-1}\right)$ 水曲柳(Fraxinus mandshurica) 幼苗的细根特征, 发现 1-3级细根长
度、表面积和比根长等特征值都随着氮浓度提高而 增大, 低氮处理 $\left(1 \mathrm{mmol} \cdot \mathrm{L}^{-1}\right)$ 显著增加了水曲柳幼苗 1 级根的直径但降低了 1-2级根的数量, 且细根直径 增加与细根横切面皮层细胞直径和皮层厚度的增加 有关; 而高氮 $\left(16 \mathrm{mmol} \cdot \mathrm{L}^{-1}\right)$ 将导致皮层细胞直径减 小和皮层厚度缩窄。本研究结果表明: 缺氮 $(0$ $\left.\mathrm{mmol} \cdot \mathrm{L}^{-1}\right)$ 和高氮 $\left(20 \mathrm{mmol} \cdot \mathrm{L}^{-1}\right)$ 均可抑制杨树幼苗各 级根序细根的形态建成(表2), 尤其1-3级细根干质 量低于正常氮水平 $\left(10 \mathrm{mmol} \cdot \mathrm{L}^{-1}\right)$, 这可能是由于不 同氮素浓度影响到根系细胞分裂并引发细根组织密 度的变化所导致。4-5级细根在不同氮素水平下的形 态差异大部分不显著, 这说明氮素主要影响低级细 根的生长和发育。比根长是细根功能性状的重要指 标, 本研究发现其随氮素水平升高而逐渐减小。因 此, 氮素虽然在根系形态构建中发挥着重要作用, 但是氮素有效性与细根形态建成并不具有线性关 系。大田人工林施肥试验也证实了类似的规律性, 如火炬松(Pinus teada) 和美国黄松(Pinus ponderosa) 人工林在施氮肥时根系表面积、直径和总长度增加, 但比根长显著减小(King et al., 1997); 水曲柳和落 叶松人工林施加氮肥降低了两树种低级根序的生物 量、直径和比根长(刘金梁等, 2009)。丁国泉等(2010) 对日本落叶松(Larix kaempferi)的研究表明, 施氮肥 可降低1-5级细根平均根长和表面积, 增加细根直 径和比根长。Kern等(2004)对美洲黑杨 (Populus deltoides)人工林施加氮肥的研究也发现, 随着氮肥 施加量的增加, 杨树细根生长量并未呈现线性增 长。因此, 在杨树人工林经营过程中, 选择合适的氮 素浓度适度施肥有利于杨树细根的生长, 反之则可 能导致杨树细根生长受抑制, 引起林木生长量下 降。氮素有效性调控根系生长机理比较复杂, 关于 氮素有效性与人工林生产力的关系仍是今后应该重 点关注的问题。

杨树是具有一定化感作用的树种(祝心如和王 大力, 1997; 万开元等, 2005), 王延平等(2010)通过 根系分泌物收集装置分离鉴定了杨树根系分泌的几 种酚酸类物质。研究表明, 酚酸对植物本身具有较 强的化感毒性(Rice, 1984; Li et al., 2010), 且酚酸对 根系生长的影响在组织解剖结构上得到了证实。如, 紫花苜宿 (Medicago sativa) 叶片水溶性酚类物质对 幼苗根系生长显著抑制, 根尖组织细胞被严重破坏 以致影响根组织分化(Chon et al., 2002); 苯甲酸 
(benzoic acid)使芥菜(Brassica juncea)根尖细胞呈无 规则排列并且细胞器破裂(Kaur et al., 2005)。酚酸对 杨树根系生长的影响在根系形态特征上表现也十分 明显，杨阳等(2010)通过模拟酚酸环境，发现酚酸 能显著抑制杨树幼苗根系生长, 酚酸处理 40 天的杨 树幼苗平均根尖数、根长、根系表面积、根系分枝 数以及根系分形维数较对照显著降低, 而幼苗根系 直径则显著增大。本研究仿生田间土壤酚酸浓度设 置 $0.5 X$ 和 $1.0 X$ 两种酚酸环境, 进一步发现酚酸处理 显著影响了杨树 1-2级细根直径和体积, 且细根体 积和直径随酚酸浓度增加显著增大。在杨阳等 (2010)的试验研究中, $0.5 X$ 和 $1.0 X$ 两种酚酸环境中杨 树细根根尖数、根表面积、分枝数等特征均未呈现 显著差异, 但根直径在 $1.0 X$ 环境中显著高于 $0.5 X$ 环 境。本研究结果与其结论存在一致性, 同时进一步 说明了酚酸对杨树细根形态影响的主效应中也体现 出与根序的高度相关性(图4), 酚酸对杨树细根直径 的影响主要体现在对低根序细根直径的增加。此外, 本研究为仿生杨树人工林土壤酚酸环境, 考虑到酚 酸在人工林根际土壤中的累积规律, 仅选择了 $0.5 X$ 和 $1.0 X$ 两种酚酸浓度, 并未进一步设置较高浓度的 酚酸环境。有研究表明, 低浓度酚酸对根系内超氧 化物歧化酶和过氧化物酶等保护酶活性具有促进作 用(Devi \& Prasad, 1996), 而随着酚酸浓度的提高, 酚酸诱发的伤害超出植株自我保护能力(Baziramakenga et al., 1995; 吕卫光等, 2002), 并导致丙二醛 等有害物质的积累(Politycka, 1996)。如果继续提高 酚酸浓度, 杨树细根构型将受到严重影响, 包括细 根数量显著下降, 根长和根表面积显著减少等(杨 阳等, 2010)。基于此, 本研究中酚酸对杨树细根各 根序形态的影响由于更符合田间土壤实际状态, 在 一定程度上反映了杨树人工林细根的生长规律。

本研究结果表明, 杨树不同根序细根形态对酚 酸和氮素交互作用的响应存在差异, 这说明划分根 序研究细根形态是十分必要的。此外, 酚酸和氮素 对细根形态的影响可能具有协同或拮抗效应, 这导 致不同根序的细根形态对两者的响应规律不同。在 本研究中, 虽然氮素对杨树细根形态影响的主效应 大于酚酸(图4), 但是两者的交互效应对细根长度、 表面积、比根长等形态参数均产生了显著影响。这 说明, 酚酸及氮素有效性都无法独立成为影响细根 生长的环境因子。冗余分析表明, 酚酸主要影响细
根直径、体积、干质量、根组织密度等, 这些指标 较好地刻画了根系形态建成特征; 而氮素主要影响 细根长度、表面积等, 这些形态与根系受食关系密 切。实际上, 伴随着根系吸收, 根际周围有效态氮将 很快耗尽, 细根出现衰老而死亡, 根系只有不断生 长出新细根才能拓展空间受食氮素 (Eissenstat, 1997)。因此, 细根长度受氮素有效性的影响十分显 著, 比根长即是体现细根吸收功能的重要指标。同 时, 伴随着细根衰老和死亡, 大量酚酸物质进入土 壤, 并经由土壤胶体吸附、微生物降解等一系列过 程后, 在根际土壤中形成累积(王延平和王华田, 2010)。酚酸的根际沉降一方面可与土壤养分离子发 生络合、螯溶等非生物化学过程, 从而造成土壤有 效养分含量下降(Chapin III, 1995), 另一方面也可 能影响到土壤酶活性和微生物群落结构, 继而影响 土壤养分的矿化过程(Kong et al., 2008; Qu \& Wang, 2008)。因此, 酚酸与氮素在根际环境中存在相互作 用, 根际酚酸物质的累积可显著改变土壤养分环境 (Inderjit \& Duke, 2003), 使土壤的含氮量维持在很 低的水平(Rice, 1984)。细根形态特征的变化在一定 程度上反映出根系在根际过程交互效应下的形态构 建和受食特征, 这对今后深入研究树木根际过程对 光合产物碳分配的影响机制具有重要意义。

基金项目 国家重点基础研究发展计划项目(2012CB416904)、国家自然科学基金(31170662 和 31270670)、山东省自然科学基金(ZR2012CM033) 和山东省博士后创新基金(2014140687)。

\section{参考文献}

Baziramakenga R, Leroux GD, Simard RR (1995). Effects of benzoic and cinnamic acids on membrane permeability of soybean roots. Journal of Chemical Ecology, 21, 12711285.

Block RMA, van Rees KCJ, Knight JD (2006). A review of fine root dynamics in Populus plantations. Agroforestry Systems, 67, 73-84.

Bloomfield J, Vogt KA, Wargo PM (1996). Tree root turnover and senescence. In: Waisel Y, Eshel A, Kafkafi U eds. Plant Roots, The Hidden Half. 2nd ed. Marcel Dekker Press, New York. 363-381.

Chapin III FS (1995). New cog in the nitrogen cycle. Nature, 377, 199-200.

Chen HB, Wei X, Wang J, Wang ZQ (2010). Morphological and anatomical responses of Fraxinus mandshurica seedling roots to different nitrogen concentrations. Scientia Silvae Sinicae, 46(2), 61-66. (in Chinese with English 
abstract) [陈海波, 卫星, 王婧, 王政权 (2010). 水曲柳 苗木根系形态和解剖结构对不同氮浓度的反应. 林业 科学, 46(2), 61-66.]

Chon SU, Choi SK, Jung S, Jang HG, Pyo BS, Kim SM (2002). Effects of alfalfa leaf extracts and phenolic allelochemicals on early seedling growth and root morphology of alfalfa and barnyard grass. Crop Protection, 21, 1077-1082.

Devi SR, Prasad MNV (1996). Ferulic acid mediated changes in oxidative enzymes of maize seedlings: Implications in growth. Biologia Plantarum, 38, 387-395.

Ding GQ, Yu LZ, Wang ZQ, Hu WL, Zheng Y, Jin X, Ding L, Xu QX (2010). Effects of fertilization on fine root morphology of Larix kaempferi. Journal of Northeast Forestry University, 38(5), 16-19. (in Chinese with English abstract) [丁国泉, 于立忠, 王政权, 胡万良, 郑颖, 金金金, 丁否, 徐庆祥 (2010). 施肥对日本落叶松细根形态的影 响. 东北林业大学学报, 38(5), 16-19.]

Eissenstat DM (1997). Trade-offs in root form and function. In: Jackson LE ed. Ecology in Agriculture. Academic Press, San Diego, USA. 173-199.

Fitter AH, Self GK, Wolfenden J, van Vuuren MMI, Brown TK, Williamson L, Graves JD, Robinson D (1996). Root production and mortality under elevated atmospheric carbon dioxide. Plant and Soil, 187, 299-306.

Guo DL, Fan PP (2007). Four hypotheses about the effects of soil nitrogen availability on fine root production and turnover. Chinese Journal of Applied Ecology, 18, 2354-2360. (in Chinese with English abstract) [ 郭大立, 范萍萍 (2007). 关于氮有效性影响细根生产量和周转率的四个 假说. 应用生态学报, 18, 2354-2360.]

Hodge A (2004). The plastic plant: Root responses to heterogeneous supplies of nutrients. New Phytologist, 162, 924.

Inderjit, Duke SO (2003). Ecophysiological aspects of allelopathy. Planta, 217, 529-539.

Inderjit, Mallik AU (1997). Effect of phenolic compounds on selected soil properties. Forest Ecology and Management, 92, 11-18.

Jones DL, Nguyen C, Finlay RD (2009). Carbon flow in the rhizosphere: Carbon trading at the soil-root interface. Plant and Soil, 321, 5-33.

Kaur H, Inderjit, Kaushik S (2005). Cellular evidence of allelopathic interference of benzoic acid to mustard (Brassica juncea L.) seedling growth. Plant Physiology and Biochemistry, 43, 77-81.

Kern CC, Friend AL, Johnson JMF, Coleman MD (2004). Fine root dynamics in a developing Populus deltoides plantation. Tree Physiology, 24, 651-660.

King JS, Thomas RB, Strain BR (1997). Morphology and tissue quality of seedling root systems of Pinus taeda and Pinus ponderosa as affected by varying $\mathrm{CO}_{2}$, temperature, and nitrogen. Plant and Soil, 195, 107-119.
Kong CH, Chen LC, Xu XH, Wang P, Wang SL (2008). Allelochemicals and activities in a replanted Chinese fir (Cunninghamia lanceolata (Lamb.) Hook) tree ecosystem. Journal of Agricultural and Food Chemistry, 56, 11734 11739.

Li ZH, Wang Q, Ruan X, Pan CD, Jiang DA (2010). Phenolics and plant allelopathy. Molecules, 15, 8933-8952.

Liu FD, Jiang YZ, Wang HT, Kong LG, Wang Y (2005). Effect of continuous cropping on poplar plantation. Journal of Soil and Water Conservation, 19(2), 102-105. (in Chinese with English abstract) [刘福德, 姜岳忠, 王华田, 孔令 刚, 王迎 (2005). 杨树人工林连作效应的研究. 水土保 持学报, 19(2), 102-105.]

Liu JL, Mei L, Gu JC, Quan XK, Wang ZQ (2009). Effects of nitrogen fertilization on fine root biomass and morphology of Fraxinus mandshu-rica and Larix gmelinii: A study with in-growth core approach. Chinese Journal of Ecology, 28, 1-6. (in Chinese with English abstract) [刘金梁, 梅莉, 谷加存, 全先奎, 王政权 (2009). 内生长法研究 施氮肥对水曲柳和落叶松细根生物量和形态的影响. 生态学杂志, 28, 1-6.]

Lü WG, Zhang CL,Yuan F, Peng Y (2002). Mechanism of allelochemicals inhibiting continuous cropping cucumber growth. Scientia Agricultura Sinica, 35, 106-109. (in Chinese with English abstract) [吕卫光, 张春兰, 袁飞, 彭宇 (2002). 化感物质抑制连作黄瓜生长的作用机理. 中国农业科学, 35, 106-109.]

Martens DA (2002). Relationship between plant phenolic acids released during soil mineralization and aggregate stabilization. Soil Science Society of America Journal, 66, 18571867.

Norby RJ, Jackson RB (2000). Root dynamics and global change: Seeking an ecosystem perspective. New Phytologist, 147, 3-12.

Osmont KS, Sibout R, Hardtke CS (2007). Hidden branches: Developments in root system architecture. Annual Review of Plant Biology, 58, 93-113.

Politycka B (1996). Peroxidase activity and lipid peroxidation in roots of cucumber seedlings influenced by derivatives of cinnamic and benzoic acids. Acta Physiologiae Plantarum, 18, 365-370.

Pregitzer KS, DeForest JL, Burton AJ, Allen MF, Ruess RW, Hendrick RL (2002). Fine root architecture of nine North American trees. Ecological Monographs, 72, 293-309.

Qu XH, Wang JG (2008). Effect of amendments with different phenolic acids on soil microbial biomass, activity, and community diversity. Applied Soil Ecology, 39, 172-179.

Rice EL (1984). Allelopathy. 2nd ed. Academic Press, London. $9-10$.

Ruffel S, Krouk G, Ristova D, Shasha D, Birnbaum KD, Coruzzi GM (2011). Nitrogen economics of root foraging: Transitive closure of the nitrate-cytokinin relay and 
distinct systemic signaling for $\mathrm{N}$ supply vs. demand. Proceedings of the National Academy of Sciences of the United States of America, 108, 18524-18529.

Schweinsberg-Mickan MSZ, Jörgensen RG, Müller T (2012). Rhizodeposition: Its contribution to microbial growth and carbon and nitrogen turnover within the rhizosphere. Journal of Plant Nutrition and Soil Science, 175, 750-760.

Sun CL, Zhu ZX, Wang Z, Tong CR (1995). Study on the soil degradation of the poplar plantation and the technique to preserve and increase soil fertility. Scientia Silvae Sinicae, 31, 506-512. (in Chinese with English abstract) [孙翠玲, 朱占学, 王珍, 佟超然 (1995). 杨树人工林地力退化及 维护与提高土壤肥力技术的研究. 林业科学, 31, 506512.]

Sun Y, Xu XL, Kuzyakov Y (2014). Mechanisms of rhizosphere priming effects and their ecological significance. Chinese Journal of Plant Ecology, 38, 62-75. (in Chinese with English abstract) [孙悦, 徐兴良, Kuzyakov Y (2014). 根际激发效应的发生机制及其生态重要性. 植物生态学报, 38, 62-75.]

Tan XM, Wang HT, Kong LG, Wang YP (2008). Accumulation of phenolic acids in soil of a continuous cropping poplar plantation and their effects on soil microbes. Journal of Shandong University (Natural Science), 43, 14-19. (in Chinese with English abstract) [谭秀梅, 王华田, 孔令 刚, 王延平 (2008). 杨树人工林连作土壤中酚酸积累规 律及对土壤微生物的影响. 山东大学学报(理学版), 43, 14-19.]

Valenzuela-Estrada LR, Vera-Caraballo V, Ruth LE, Eissenstat DM (2008). Root anatomy, morphology, and longevity among root orders in Vaccinium corymbosum (Ericaceae). American Journal of Botany, 95, 1506-1514.

Wan KY, Chen F, Yu CB, Zhong ZX (2005). Allelopathy and its application in poplar-corps system. Ecologic Science, 24, 57-60. (in Chinese with English abstract) [万开元, 陈 防, 余常兵, 钟志祥 (2005). 杨树-农作物复合系统中 的化感作用. 生态科学, 24, 57-60.]

Wang HT, Wang YP (2013). Hotspot discussion on decline mechanism of replanted plantation. Journal of Shandong University (Natural Science), 48(7), 1-8. (in Chinese with English abstract) [王华田, 王延平 (2013). 关于连作人 工林衰退机理几个热点问题的探讨. 山东大学学报(理 学版), 48(7), 1-8.]

Wang YP, Wang HT (2010a). Allelochemicals from roots exudation and its environment behavior in soil. Chinese Journal of Soil Science, 41, 501-507. (in Chinese with English abstract) [王延平, 王华田 (2010a). 植物根分泌 的化感物质及其在土壤中的环境行为. 土壤通报, 41 , 501-507.]

Wang YP, Wang HT, Yang Y, Jiang YZ, Wang ZQ (2010b). Study on adsorption and retention of exogenous phenolic acids in the soil of poplar (Populus deltoids Marsh) plantation. Journal of Soil and Water Conservation, 24, 251-256. (in Chinese with English abstract) [王延平, 王 华田, 杨阳, 姜岳忠, 王宗芹 (2010b). 外源酚酸在杨树 人工林土壤中的吸附与滞留动态研究. 水土保持学报, 24, 251-256.]

Wang YP, Wang HT, Jiang YZ, Chen HY, Ni GP (2011). Secretion dynamics of phenolic acids from poplar (Populus $\times$ euramericana 'Neva') seedling roots under N, P deficiency conditions. Scientia Silvae Sinicae, 47(1), 73-79. (in Chinese with English abstract) [王延平, 王华田, 姜岳 忠, 陈鸿鹰, 倪桂萍 (2011). 氮磷亏缺条件下杨树幼苗 根系分泌酚酸的动态. 林业科学, 47(1), 73-79.]

Wang YP, Wang HT, Xu T, Ni GP, Jiang YZ (2013). Effects of exogenous phenolic acid on soil nutrient availability and enzyme activities in a poplar plantation. Chinese Journal of Applied Ecology, 24, 667-674. (in Chinese with English abstract) [王延平, 王华田, 许坛, 倪桂萍, 姜岳忠 (2013). 酚酸对杨树人工林土壤养分有效性及酶活性的 影响. 应用生态学报, 24, 667-674.]

Xu T, Wang HT, Wang YP, Han YF, Jiang YZ, Zhu WR (2014). Correlation between soil nutrient availability and bacteria community succession in poplar plantations. Chinese Journal of Applied and Environmental Biology, 20, 491-498. (in Chinese with English abstract) [许坛, 王华 田, 王延平, 韩亚飞, 姜岳忠, 朱婉䒘 (2014). 杨树人 工林土壤养分有效性变化及其与土壤细菌群落演变的 相关性. 应用与环境生物学报, 20, 491-498.]

Xu T, Wang HT, Zhu WR, Wang YP, Li CR, Jiang YZ (2015). Morphological and anatomical traits of poplar fine roots in successive rotation plantations. Scientia Silvae Sinicae, 51, 119-126. (in Chinese with English abstract) [许坛, 王华 田, 朱婉芮, 王延平, 李传荣, 姜岳忠 (2015). 连作杨 树细根根序形态及解剖结构. 林业科学, 51, 119-126.]

Yang Y, Wang HT, Wang YP, Jiang YZ, Wang ZQ (2010). Effects of exogenous phenolic acids on root physiologic characteristics and morphologic development of poplar hydroponic cuttings. Scientia Silvae Sinicae, 46(11), 73-80. (in Chinese with English abstract) [杨阳, 王华田, 王延平, 姜岳忠, 王宗芹 (2010). 外源酚酸对杨树幼苗 根系生理和形态发育的影响. 林业科学, 46(11), 73-80.]

Zhu XR, Wang DL (1997). Potential effect of extracts of roots of Malus pumila and Populus canadensis on wheat growth. Acta Phytoecologica Sinica, 21, 226-233. (in Chinese with English abstract) [祝心如, 王大力 (1997). 苹果、杨树等林木根系浸取物对小麦生长的潜在影响. 植物生态学报, 21, 226-233.]

责任编委: 王政权 责任编辑: 王 葳

www.plant-ecology.com 